\title{
Extramammary Perianal Paget's Disease
}

\author{
M.N. Al Hallak N. Zouain
}

University of North Dakota School of Medicine, MeritCare Health System, Roger

Maris Cancer Center, Department of Radiation, Fargo, N. Dak., USA

\section{Key Words}

Extramammary Paget's disease $\cdot$ Adenocarcinoma $\cdot$ Treatment

\begin{abstract}
Perianal Paget's disease is a rare malignancy. It is rarely isolated and often associated with an underlying adenocarcinoma. It usually presents with anal itchiness and discomfort and can be misdiagnosed as hemorrhoids. Once the diagnosis of perianal Paget's disease is granted, extensive work-up to find an underlying primary malignancy is crucial. Surgery is the standard modality of treatment of extramammary Paget's disease (EMPD) with recurrence rates of $44-60 \%$. Other different treatment modalities including radiotherapy, laser therapy, topical and systemic chemotherapy and the new emerging, promising photodynamic therapy are in the field of study. A 76-year-old man was referred to our hospital with a one-year history of anal itchiness and intermittent rectal bleeding. Skin shave and punch biopsies from the perianal area were reported back as perianal Paget's disease with no underlying adenocarcinoma. The immunohistochemical stains were positive for cytokeratin 7 but also positive for cytokeratin 20 and CEA which indicated the essentiality of extensive investigations to find a primary malignancy. Skin exam showed no primary source. The investigations were unable to find the primary malignancy. Given the results of immunohistochemical stains we recommended local perianal Paget's disease resection. The intraoperative frozen section showed adenocarcinoma around the anal sphincter. Ten days later the patient underwent an abdominoperineal resection and the final pathology report showed extensive adenocarcinoma in three quadrants of the perianal area with focal involvement of the rectal mucosa. We recommended an adjuvant chemotherapy with FOLFOX following surgery given the bulkiness of the disease. We conclude that once perianal Paget's disease is diagnosed, an extensive work-up should be done to find the underlying primary malignancy. Immunohistochemical stains are helpful in raising the suspicion of underlying primary malignancy. Finding an underlying primary malignancy in patients with EMPD is prompt to choose the treatment modality and estimate the prognosis.
\end{abstract}




\section{Introduction}

A malignant change of the areola skin in association with underlying breast carcinoma was first reported by Sir James Paget in 1874 [1]. However, perianal extramammary Paget's disease (EMPD) was first described in 1893 [2]. It affects individuals between the ages of 50 and 80 years and is more common in women and white-skinned races [3]. EMPD is a usually noninvasive adenocarcinoma of the skin outside of the mammary gland and the most frequently affected site is the vulva, followed by perineal, perianal, scrotal and penile skin. Less commonly, the axilla, buttocks, thighs, eyelids and external auditory canal may be affected [4]. The origin of the neoplastic cells could be apocrine glands or epithelial stem cells. Skin areas rich in apocrine glands such as the genital region are typical sites of EMPD.

The signs and symptoms are a skin lesion often mistaken as an eczema that may be itchy or painful. A biopsy will establish the diagnosis. The histology of the lesion is the same as for Paget's disease of the breast. The disease is rare and only fewer than 300 cases have been reported in the literature [5]. The rate of malignancy associated with perianal Paget's disease ranges from 33 to 86\% [6]. The majority are colorectal and tubo-ovarian cancers. If present, an underlying invasive carcinoma carries a poor prognosis [7-9]. Therefore search for an underlying primary is essential before any treatment [10].

The treatment of perianal Paget's disease is essentially surgical. Wide local excision is the preferred approach for noninvasive, locally confined disease [11-15]. When the disease is associated with an underlying carcinoma of the anus or rectum, the procedure of choice is an abdominoperineal resection with wide excision of the cutaneous lesion [5]. The recurrence rates after surgery range between 44 and $60 \%[3,6,7,16]$ and thus prompt other treatment modalities including radiotherapy, laser therapy, topical and systemic chemotherapy and the new emerging, promising photodynamic therapy to be in the field of study.

\section{Case Report}

A 76-year-old man was referred to our hospital with a one-year history of perianal irritation and intermittent rectal bleeding. The patient had neither weight loss nor further gastrointestinal symptoms. He had no family history of colon cancer or Paget's disease, but his mother had a history of malignant skin melanoma. The physical exam was unremarkable with no suspicious skin lesions but small external hemorrhoids which were not tender. There was no lymphadenopathy appreciated. The patient received treatment with topical cortisone cream without improvement. A sigmoidoscopy was done and came back negative. The external hemorrhoids were cauterized. Nevertheless the patient continued to complain of the perianal irritation so local steroid injections were given with minimal relief.

A perianal shaved biopsy was done and the pathology report came back as perianal EMPD. Properly controlled immunohistochemical stains were positive for cytokeratin 7 (a sensitive marker for almost all pagetoid neoplasms of the breast and genital skin), also positive for cytokeratin 20 and CEA (which indicates the essentiality to find out underlying primary malignancy [17]) but negative for HMB-45 (which is positive in melanoma). Mucicarmine stain was positive as well. The serum CEA marker was negative. A repeat punch biopsy of the perianal lesion was done and the pathology was reviewed by two university hospitals. It confirmed the diagnosis of perianal Paget's disease and was negative for any underlying adenocarcinoma.

A CT scan for the chest, abdomen and pelvis was negative. A colonoscopy was done and showed a large sessile polyp in the cecum, three small benign polyps in the right colon and some scattered small polyps in the transverse colon which were all removed and the pathology confirmed the benign process. Given the results of immunohistochemical stains which raised the suspicion, we recommended local wide excision of the perianal area containing the Paget's disease lesion. To the surprise of the surgical team, the frozen section showed extensive underlying invasive moderately differentiated 
adenocarcinoma surrounding the anal sphincter. The margins were positive for remaining adenocarcinoma, so ten days later the patient underwent abdominoperineal resection with sigmoidectomy and permanent colostomy was granted.

The final pathology showed EMPD involving all four quadrants of the perianal area with invasive adenocarcinoma involving three quadrants of the perianal area. The pathology also reported extension of Paget's disease into the anal gland ducts and involvement of the rectal mucosa. There was no evidence of angiolymphatic invasion, but the adenocarcinoma was focally invading the underlying muscles. Thirteen lymph nodes were removed and reported as benign. We recommended to the patient a course of FOLFOX-based adjuvant chemotherapy following surgery given the bulkiness of the disease in the pelvis and the involvement of the anal sphincter.

Six-month follow-up showed no recurrence of Paget's disease or adenocarcinoma. The patient had side effects from the chemotherapy including neutropenia which required leukine injections. He could not complete the seventh cycle secondary to allergic reaction to oxaliplatin including flushing, diaphoresis and itching with nausea, so the infusion was stopped. The reaction subsided immediately but the patient did not prefer to be re-challenged so the subsequent cycles were 5-fluorouracil-based only. The patient has good energy level with good appetite and no urinary symptoms have been reported so far.

\section{Discussion}

EMPD is a rare malignancy. Once the diagnosis of EMPD is granted, an extensive work-up should be done to rule out underlying primary malignancy. Suitable investigations may include: pelvic ultrasound scan, hysteroscopy, laparoscopy and/or an MRI scan of the pelvis; colonoscopy, sigmoidoscopy and/or barium enema; cystoscopy and IVP; mammogram and chest X-ray [18].

Surgery is the standard modality of treatment of EMPD with recurrence rates of 44$60 \%[3,6]$. The reason behind the high recurrence rate even after extensive resection is the multicentric nature of EMPD which causes the intrasurgical frozen section analysis of the margins to be misleading [19]. Moh's micrographic surgery has shown promise for reducing local recurrence rates in EMPD [20].

Radiation therapy is also a modality to treat EMPD. There are no randomized controlled trials to compare surgery with radiation therapy for EMPD. However, radiation therapy for EMPD may be indicated in patients medically unfit for surgery, for recurrence following surgery, in any patient who wishes to preserve the functional and structural integrity of the vulva by avoiding multiple surgeries, or as an adjuvant to surgery in patients with an underlying adenocarcinoma, where there is a high risk of local recurrence with surgery alone [21].

Topical chemotherapeutic agents including 5-fluorouracil (5-FU), bleomycin and imiquimod have been used to treat EMPD. 5-FU may be useful for symptomatic relief, preoperative delineation of disease extent, cytoreduction prior to surgery and postoperative detection of early disease recurrence $[22,23]$. Bleomycin was used by Watring et al. to treat patients with recurrent vulval EMPD with no associated invasive carcinoma and achieved 57\% complete remission [24]. Imiquimod was reported to achieve clinical and histological cure $[25,26]$. Systemic chemotherapy is also used to treat EMPD with different combinations available. Case reports have recorded complete response to mitomycin $\mathrm{C}$ and 5-FU [27] and carboplatin and 5-FU [28]. Watanabe at al. reported one complete response when using a combination of mitomycin $\mathrm{C}$, etoposide and cisplatin in three patients with partial response in the other two [29]. Systemic chemotherapy can be recommended if surgery and radiotherapy are contraindicated [3]. 
Photodynamic therapy is a new emerging and promising modality for treating EMPD since the mid-nineties [30]. This technique uses a tumor localizing photoreactive drug like 5-aminolevulinic acid (5-ALA) with appropriate wavelength light to destroy the tumor cells [31]. Shieh et al. [30] treated five patients with EMPD and were successful in three of five patients who achieved complete response. More recently Li et al. [32] reported a patient with perianal EMPD and achieved complete cure after the second course of photodynamic therapy. They used topical 5-ALA in the first session of treatment and topical 5-ALA with intravenous HiPorfin in the second session.

Laser therapy for EMPD appears to carry a very high recurrence rate [33]. Some authors have used $\mathrm{CO}_{2}$ laser ablation guided by photodynamic diagnosis using ALA-induced fluorescence [34].

The functional results after repair of large perianal defects are acceptable and overall quality of life is similar to the normal population although a large proportion of patients have some form of incontinence that impacts certain aspects of their quality of life [35].

We conclude that once perianal Paget's disease is diagnosed, an extensive work-up should be done to find the underlying primary malignancy. Immunohistochemical stains are helpful in raising the suspicion of underlying primary malignancy especially with positive cytokeratin 20 and CEA [17]. Finding an underlying primary malignancy in patients with EMPD is prompt to choose the treatment modality and estimate the prognosis. If the patient has an extensive underlying primary adenocarcinoma with positive margins in the local wide excision, an abdominoperineal resection should be considered. We recommended to our patient a course of adjuvant chemotherapy with FOLFOX after surgery, given the disease bulkiness and the involvement of the anal sphincter. 


\section{References}

1 Paget J: On disease of the mammary areola preceding cancer of the mammary gland. St Bartholemew Hosp Res Lond 1874;10:87-89.

2 Darier J, Coulillaud P: Sur un cas de maladie de Paget de la région périnéo-anale et scrotale. Ann Dermatol Syphiligr 1893;4:25-31.

- 3 Zollo JD, Zeitouni NC: The Roswell Park Cancer Institute experience with extramammary Paget's disease. Br J Dermatol 2000;142:59-65.

4 Heymann WR: Extramammary Paget's disease. Clin Dermatol 1993;11:83-87.

5 Berardi RS, Lee S, Chen HP: Perianal extramammary Paget's disease. Surg Gynecol Obstet 1988;167:359-365.

6 Sarmiento JM, Wolff BG, Burgart LJ, Frizelle FA, Ilstrup DM: Paget's disease of the perianal region - an aggressive disease? Dis Colon Rectum 1997;40:11871194.

7 Beck DE, Fazio VW: Perianal Paget's disease. Dis Colon Rectum 1987;30:263-266.

-8 Shutze WP, Gleysteen JJ: Perianal Paget's disease. Classification and review of management: report of two cases. Dis Colon Rectum 1990;33:502-507.

9 Williams SL, Rogers LW, Quan SH: Perianal Paget's disease: report of seven cases. Dis Colon Rectum 1976;19:30-40.

10 Butler JD, Hershman MJ, Wilson CA, Bryson JR: Perianal Paget's disease. J R Soc Med 1997;90:688-689.

11 Tjandra J: Perianal Paget's disease: report of three cases. Dis Colon Rectum 1988;31:462-466.

12 Marchesa P, Fazio VW, Oliart S, Goldblum JR, Lavery IC, Milson JW: Long-term outcome of patients with perianal Paget's disease. Ann Surg Oncol 1997;4:475480.

13 Goldman S, Ihre T, Logerstedt U, Svensson C: Perianal Paget's disease: report of five cases. Int J Colorectal Dis 1992;7:167-169.

- 14 McCarter MD, Quan SH, Busam K, Paty PP, Wong D, Guillem JG: Long-term outcome of perianal Paget's disease. Dis Colon Rectum 2003;46:612-616.

15 Mehta NJ, Torno R, Sorra T: Extramammary Paget's disease. Southern Med J 2000;93:713-716.

16 Jensen SL, Sjølin KE, Shokouh-Amiri MH, Hagen K, Harling H: Paget's disease of the anal margin. Br J Surg 1988;75:1089-1092.

17 Lloyd J, Flanagan AM: Mammary and extramammary Paget's disease. J Clin Pathol 2000;53:742-749.

18 Shepherd V, Davidson EJ, Davies-Humphreys J: Extramammary Paget's disease. BJOG 2005;112:273-279.

-19 Fishman DA, Chambers SK, Schwartz PE, Kohorn EI, Chambers JT: Extramammary Paget's disease of the vulva. Gynecol Oncol 1995;56:266-270.

20 Mohs FE, Blanchard L: Microscopically controlled surgery for extramammary Paget's disease. Arch Dermatol 1979;115:706-708.

21 Guerrieri M, Back MF: Extramammary Paget's disease: role of radiation therapy. Australas Radiol 2002;46:204-208.

22 Bewley AP, Bracka A, Staughton RC, Bunker CB: Extramammary Paget's disease of the scrotum: treatment with topical 5-fluorouracil and plastic surgery. $\mathrm{Br} \mathrm{J}$ Dermatol 1994;131:445-446.

-23 Del Castillo LF, Garcia C, Schoendorff C, Garcia JF, Torres LM, Garcia Almagro D: Spontaneous apparent clinical resolution with histologic persistence of a case of extramammary Paget's disease: response to topical 5-fluorouracil. Cutis 2000;65:331-333.

24 Watring WG, Roberts JA, Lagasse LD, et al: Treatment of recurrent Paget's disease of the vulva with topical bleomycin. Cancer 1978;41:10-11.

25 Zampogna JC, Flowers FP, Roth WI, Hassenein AM: Treatment of primary limited cutaneous extramammary Paget's disease with topical imiquimod monotherapy: two case reports. J Am Acad Dermatol 2002;47:S229-S235.

26 Mirer E, El Sayed F, Ammoury A, Lamant L, Messer L, Bazex J: Treatment of mammary and extramammary Paget's skin disease with topical imiquimod. J Dermatolog Treat 2006;17:167-171. 
27 Thirlby RC, Hammer CJJ, Galagan KA, Travaglini JJ, Picozzi VJJ: Perianal Paget's disease: successful treatment with combined chemoradiotherapy. Report of a case. Dis Colon Rectum 1990;33:150-152.

-28 Yamazaki N: Chemotherapy for advanced adenocarcinoma of the skin: experience with combination chemotherapy and a review of the literature. Gan To Kagaku Ryoho 1997;24:30-36.

29 Watanabe Y, Hoshiai H, Ueda H, Nakai H, Obata K, Noda K: Low-dose mitomycin C, etoposide, and cisplatin for invasive vulvar Paget's disease. Int $\mathrm{J}$ Gynecol Cancer 2002;12:304-307.

30 Shieh S, Dee AS, Cheney RT, Frawley NP, Zeitouni NC, Oseroff AR: Photodynamic therapy for the treatment of extramammary Paget's disease. Br J Dermatol 2002;146:1000-1005.

-31 Dougherty TJ, Gomer CJ, Henderson BW, et al: Photodynamic therapy. J Natl Cancer Inst 1998;90:889-905.

- 32 Li L, Deng Y, Zhang L, Liao W, Luo R, Huang Z: Treatment of perianal Paget's disease using photodynamic therapy with assistance of fluorescence examination: case report. Lasers Med Sci 2009;24:981-984.

-33 Louis-Sylvestre C, Haddad B, Paniel BJ: Paget's disease of the vulva: results of different conservative treatments. Eur J Obstet Gynecol Reprod Biol 2001;99:253255.

-34 Becker-Wegerich PM, Fritsch C, Schulte KW, et al: Carbon dioxide laser treatment of extramammary Paget's disease guided by photodynamic diagnosis. Br J Dermatol 1998;138:169-172.

- 35 Conklin A, Hassan I, Chua HK, Wietfeldt ED, Larson DR, Thomsen KA, Nivatvongs S: Long-term functional and quality of life outcomes of patients after repair of large perianal skin defects for Paget's and Bowen's disease. J Gastrointest Surg 2009;13:951-955. 